\title{
Corneal irregular astigmatism after laser in situ keratomileusis for myopia
}

\author{
Tae Min Baek, Kyung Hun Lee, Atsuo Tomidokoro, Tetsuro Oshika
}

\begin{abstract}
Aims-To quantitatively evaluate the changes in corneal irregular astigmatism after laser in situ keratomileusis (LASIK) in relation to the amount of laser ablation. Methods-In 189 eyes of 116 patients undergoing LASIK for myopia, corneal topography was obtained before and 1 month after surgery. Using Fourier harmonic analysis of the topography data, corneal irregular astigmatism (asymmetry and higher order irregularity) was calculated.
\end{abstract}

Results-By surgery, asymmetry component significantly increased ( $p<0.0001$, Wilcoxon signed rank test), while higher order irregularity did not $(p=0.767)$. The increases in the asymmetry component significantly correlated with ablation depth (Spearman rank correlation coefficient $\left.r_{\mathrm{s}}=0.440, \mathrm{p}<0.0001\right)$. No significant correlation was found between changes in higher order irregularity and ablation depth $\left(r_{\mathrm{s}}=0.137, \mathrm{p}=0.074\right)$.

Conclusion-LASIK significantly increases the asymmetry component of the cornea which is dependent on the amount of laser ablation.

(Br f Ophthalmol 2001;85:534-536)

Laser in situ keratomileusis (LASIK) has been widely recognised as an effective surgical procedure for correcting myopia. Although most of the patients can attain a satisfactory level of uncorrected visual acuity after surgery, impairments of functional vision have been reported, such as reduction in contrast sensitivity and induction of glare disability. ${ }^{12}$ Corneal irregular astigmatism can be the cause of deteriorated visual performance after surgery. Slight to moderate abnormalities in corneal topography after LASIK have been demonstrated by several qualitative studies. ${ }^{3-6}$ Quantitative assessment of the changes in corneal irregular astigmatism after LASIK, however, has never been conducted except for one small study which reported increased wavefront aberrations of the cornea after LASIK. ${ }^{7}$ In eyes undergoing photorefractive keratectomy, Keller et al reported significant increases in the decentration component after surgery as calculated by the fast Fourier transform of the computerised corneal topography data. ${ }^{8}$

Transformation of periodic curves into Fourier harmonic components is widely used in electrical and biomedical engineering. Fourier analysis has been also used to mathematically model the polar variations in videokeratographic power values. ${ }^{9} 10$ The harmonic components generated via this method have immediate clinical utility - for example, measures of corneal spherical equivalent power, regular astigmatism power and axis, and irregular astigmatism. ${ }^{8}$ In the current study, we used Fourier analysis to extract the nonspherocylindrical corneal power component from the videokeratography data of eyes undergoing LASIK. The aim of the current study was twofold - to quantitatively assess the induced changes in corneal irregular astigmatism by LASIK and to analyse the relation between those changes and the amount of myopic correction.

\section{Patients and methods}

LASIK was performed on 189 eyes of 116 patients with myopia, ranging in age from 19 to 53 years old (mean 27.3 (SD 6.2) years). There were 27 males and 89 females, and their preoperative refraction was -2.0 to -12.75 dioptres (D) (-6.9 (2.3) D). One hundred and nineteen eyes $(63.0 \%)$, which underwent the combined spherical and astigmatic correction, had a refractive cylinder of $0.5-4.0 \mathrm{D}$ (1.18 (0.75) D).

All surgeries were performed by two surgeons (TMB, KHL) using the VISX Star excimer laser system (VISX Inc, Santa Clara, CA, USA). Laser parameters included the following: wavelength, $193 \mathrm{~nm}$; radiant exposure (fluence), $160 \mathrm{~mJ} / \mathrm{cm}^{2}$; pulse repetition rate, 10 $\mathrm{Hz}$; average ablation depth per pulse, $0.23 \mu \mathrm{m}$ on the cornea; aspiration air flow was used for debris removal; ablation zone diameter, 6.0 $\mathrm{mm}$; transition zone, $0.35 \mathrm{~mm}$. The automated corneal shaper microkeratome (Chiron Vision Inc, Irvine, CA, USA) was used to create a hinged flap of $160 \mu \mathrm{m}$ thickness. The amount of laser ablation was $80.5(22.8) \mu \mathrm{m}$, ranging from 30 to $144 \mu \mathrm{m}$.

Corneal topography was obtained with the scanning slit topograph (Orbscan, Bausch \& Lomb, Irvine, CA, USA) before and 1 month after surgery. The maps were rejected on the basis of poor image quality, inadequate fixation, or deficit of data in the central $4 \mathrm{~mm}$ cornea. The dioptric powers of the anterior surface on polar coordinates were downloaded as an ASCII file. Using Fourier series harmonic analysis, dioptric powers on a mire ring $\mathrm{i}, \mathrm{F}_{\mathrm{i}}(\sigma)$, can be transformed into trigonometric components of the form ${ }^{9-12}$

$$
\begin{array}{r}
F_{i}(\sigma)=a_{0}+c_{1} \cos \left(\sigma-\alpha_{1}\right)+c_{2} \cos 2\left(\sigma-\alpha_{2}\right)+c_{3} \cos 3 \\
\left(\sigma-\alpha_{3}\right)+\ldots .+c_{n} \cos n\left(\sigma-\alpha_{n}\right)
\end{array}
$$

where $a_{0}$ is the spherical component of the ring, $2 \times \mathrm{c}_{1}$ the asymmetry (tilt or decentration) component, $2 \times \mathrm{c}_{2}$ the regular astigmatism 


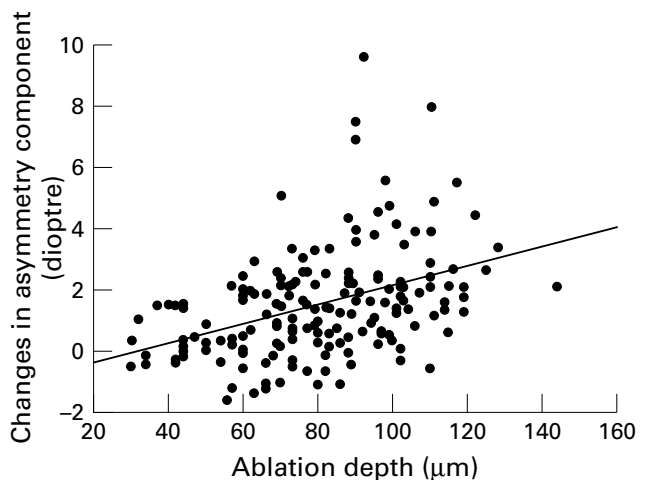

Figure 1 Significant correlation between the amount of laser ablation and changes in asymmetry component. (Spearman rank correlation coefficient $r_{s}=0.440$, $p<0.0001)$.

component, $\alpha_{2}$ the phase (or axis) of regular astigmatism, $c_{3} \ldots$ the higher order irregularity component. Among these, spherical equivalent power $\left(\mathrm{a}_{0}\right)$ and regular astigmatism (second harmonic component, $\mathrm{n}=2$ ) can be corrected by a spherocylinder lens, while the remaining components ( $\mathrm{n}=1$ and $\mathrm{n} \geqslant 3$ ) cannot, representing corneal irregular astigmatism. The lower terms, $a_{0}$ to $c_{2}$, were first calculated, and thereafter the $c_{3} \ldots$ term was obtained as the final loss of the approximation. The calculations were done for the 20 rings within the central $4 \mathrm{~mm}$ cornea, and values were averaged for the following statistical analysis.

\section{Results}

The data were analysed according to the performance of combined astigmatic correction. In 119 eyes which underwent the combined spherical and astigmatic correction, the asymmetry component significantly increased from $1.39(0.60)$ D preoperatively to 3.25 (1.77) D postoperatively ( $p<0.0001$, Wilcoxon signed rank test), while higher order irregularity was $0.25(0.10) \mathrm{D}$ before and 0.25 (0.11) D after surgery $(p=0.990)$. Similar results were obtained in the remaining 70 eyes which did not undergo astigmatic correction. The asymmetry component significantly increased from $1.24(0.53) \mathrm{D}$ preoperatively to 2.25 (1.29) D postoperatively $(\mathrm{p}<0.0001)$, and higher order irregularity was $0.22(0.12) \mathrm{D}$ before and $0.22(0.14)$ D after surgery $(\mathrm{p}=0.596)$.

In the total of 189 eyes, the asymmetry component significantly increased from $1.33(0.58)$ D preoperatively to 2.88 (1.68) D postoperatively $(\mathrm{p}<0.0001)$. Higher order irregularity did not fluctuate significantly with $0.24(0.11)$ $\mathrm{D}$ before and $0.24(0.12) \mathrm{D}$ after surgery $(\mathrm{p}=0.767)$.

The induced changes in these refractive components were analysed in relation to the amount of laser ablation. The increases in the asymmetry component significantly correlated with ablation depth (Spearman rank correlation coefficient $r_{\mathrm{s}}=0.440, \mathrm{p}<0.0001$, Fig 1). No significant correlation was found between changes in higher order irregularity and ablation depth $\left(r_{\mathrm{s}}=0.137, \mathrm{p}=0.074\right.$, Fig 2$)$.

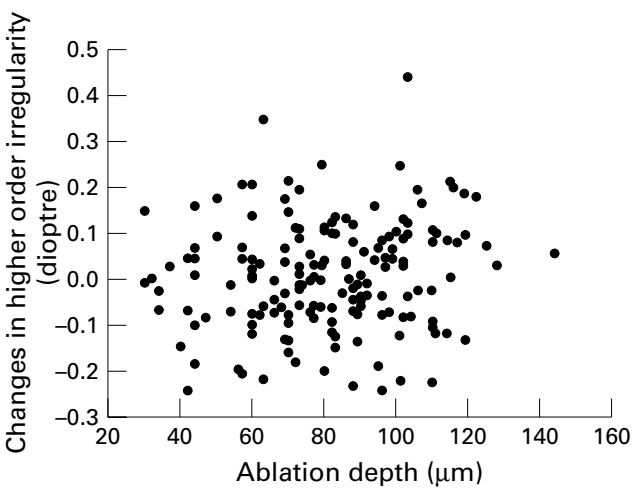

Figure 2 Relation between the amount of laser ablation and changes in higher order irregularity. There was no significant correlation (Spearman rank correlation coefficient $\left.r_{s}=0.137, p=0.074\right)$.

\section{Discussion}

In the current study, we decomposed the corneal topography data into a series of trigonometric functions using Fourier harmonic analysis, and quantified the amount of asymmetry and higher order irregularity components. These two components cannot be corrected by a spherocylindrical lens and thus are thought to represent the corneal irregular astigmatism in a broad sense. ${ }^{13}$ In eyes undergoing photorefractive keratectomy (PRK), Keller et al employed a similar technique and reported that the asymmetry component significantly increased and higher order irregularity did not change by surgery. ${ }^{8}$ The current results obtained with LASIK are compatible; a significant increase in the asymmetry component and no change in higher order irregularity.

In this study, we also found that the changes in the asymmetry component significantly correlated with the magnitude of laser ablation. In radial keratotomy ${ }^{14}$ and $\mathrm{PRK},{ }^{15}$ it has been demonstrated that the increases in corneal wavefront aberrations were dependent on the magnitude of refractive correction. A clinical study of PRK has reported that the larger amount of attempted myopic correction led to the increasing incidence of subjective symptoms, such as glare and distortion, and a lower level of patient satisfaction. ${ }^{16}$ In order to avoid severe deterioration of corneal optical quality, extremely large levels of myopic correction should be avoided.

In the current series of patients, visual acuity results were excellent regardless of the increases in the asymmetry component. Thus, as far as the high contrast visual acuity is concerned, the increase in corneal irregular astigmatism after LASIK observed herein seems to be a subclinical phenomenon. To elucidate the exact influence of corneal irregularity on the visual performance, however, further studies are needed in which more in-depth parameters have to be investigated, such as contrast sensitivity, glare visual acuity, and modulation transfer function. In fact, several studies demonstrated that many patients experience reduced contrast sensitivity as a consequence of PRK ${ }^{17-20}$ and LASIK. ${ }^{19}{ }^{21}$ Seiler et al found a high inverse correlation between 
the effective aberration and visual acuity under glare conditions after PRK. ${ }^{22}$

There should be several factors underlying the increases in the asymmetry component after LASIK, including the alignment strategy of the ablation zone. ${ }^{8}$ The excimer laser is centred on the corneal intercept of the line of sight - that is, the corneal point overlying the centre of the virtual entrance pupil rather than the corneal vertex. In contrast, Fourier derived terms are calculated relative to the videokeratoscope axis, which when correctly positioned is centred on, and normal to, the corneal vertex. The vertex and corneal intercept of the line of sight do not coincide. Thus, centring the ablation on the latter creates asymmetry when subsequently measured by the videokeratoscope. Another possible factor is the decentration of laser ablation. In previous studies, the average decentration of the LASIK ablation zone relative to the centre of the entrance pupil was reported to be approximately $0.9 \mathrm{~mm}^{23}{ }^{24}$ Although there are no data on the decentration of ablation relative to the corneal vertex, the amount of asymmetry component after LASIK would be influenced by the decentred laser ablation. Development and introduction of better centration method, such as an active eye tracking system, ${ }^{25-27}$ might help reduce the corneal irregular astigmatism induced by excimer laser surgery.

Currently, it is unclear whether and how the increases in asymmetry component influence the visual function after LASIK. In addition, no data are available at present about the long term time course of changes in asymmetry after surgery. Given the rapidly growing popularity of keratorefractive surgery, further investigation of the changes in optical quality of the cornea after surgery, by means of quantitative measures such as in the current study, is of critical importance.

None of the authors has a proprietary interest in any material or method mentioned here.

1 Perez-Santonja JJ, Sakla HF, Alio JL. Contrast sensitivity after laser in situ keratomileusis. $\mathcal{F}$ Cataract Refract Surg 1998;24:183-9.

2 Holladay JT, Dudeja DR, Chang J. Functional vision and corneal changes after laser in situ keratomileusis determined by contrast sensitivity, glare testing, and corneal topography. F Cataract Refract Surg 1999;25:663-9.

3 Hersh PS, Scher KS, Irani R. Corneal topography of photorefractive keratectomy versus laser in situ keratomileusis. Summit PRK-LASIK Study Group. Ophthalmology 1998;105:612-9.
4 Oshika T, Klyce SD. Corneal topography in LASIK. Sem Ophthalmol 1998;13:64-70.

5 Spadea L, Bianco G, Masini MC, et al. Videokeratographic changes after laser in situ keratomileusis to correct high myopia. F Cataract Refract Surg 1999;25:1589-95.

6 Barker NH, Couper TA, Taylor HR. Changes in corneal topography after laser in situ keratomileusis for myopia. $\mathcal{F}$ Refract Surg 1999;15:46-52.

7 Oshika T, Klyce SD, Applegate RA, et al. Comparison of corneal wavefront aberrations after photorefractive keratectomy and laser in situ keratomileusis. Am f Ophthalmol 1999;127:1-7.

8 Keller PR, McGhee CN, Weed KH. Fourier analysis of corneal topography data after photorefractive keratectomy. $\mathcal{F}$ Cataract Refract Surg 1998;24:1447-55.

9 Raasch TW. Corneal topography and irregular astigmatism. Optom Vis Sci 1995;72:809-15.

10 Hjortdal JØ, Erdmann L, Bek T. Fourier analysis of video-keratographic data. A tool for separation of spherical, regular astigmatic and irregular astigmatic corneal power components. Ophthalmic Physiol Opt 1995;15:171-85.

11 Olsen $\mathrm{T}$, Dam-Johansen $\mathrm{M}$, Bek $\mathrm{T}$, et al. Evaluating surgically induced astigmatism by Fourier analysis of corneal topography data. F Cataract Refract Surg 1996;22: 318-23.

12 Oshika T, Tomidokoro A, Maruo K, et al. Quantitative evaluation of irregular astigmatism by Fourier series harmonic analysis of videokeratography data. Invest Ophthalmol Vis Sci 1998;39:705-9.

13 Wyzinski P. Escalation of keratospeak: regular and irregular astigmatism. Refract Corneal Surg 1990;6:231.

14 Applegate RA, Hilmantel G, Howland HC. Corneal aberrations increase with the magnitude of radial keratotomy tions increase with the magnitude of radial kerat
refractive correction. Optom Vis Sci 1996;73:585-9.

15 Martínez CE, Applegate RA, Klyce SD, et al. Effect of pupil dilation on corneal optical aberrations after photorefractive keratectomy. Arch Ophthalmol 1998;116:1053-62.

16 Halliday BL. Refractive and visual results and patient satisfaction after excimer laser photorefractive keratectomy for myopia. Br $\mathcal{F}$ Ophthalmol 1995;79:881-7.

17 Lohmann CP, Fitzke FW, O’Bart DPS, et al. Halos-a problem for all myopes? A comparison between spectacles, contact lenses and photorefractive keratectomy. Refract Corneal Surg 1993;9(suppl):S72-5.

18 Butuner Z, Elliott DB, Gimbel HV, et al. Visual function one year after excimer laser photorefractive keratectomy. $f$ year after excimer laser photorefractiv
Refract Corneal Surg 1994;10:625-30.

19 Wang Z, Chen J, Yang B. Comparison of laser in situ keratomileusis and photorefractive keratectomy to correct myopia from -1.25 to -6.0 diopters. F Refract Surg 1997;13:528-34.

20 Ghaith AA, Daniel J, Stulting RD, et al. Contrast sensitivity and glare disability after radial keratotomy and photorefractive keratectomy. Arch Ophthalmol 1988;116:12-18.

21 Pérez-Santonja JJ, Sakla HF, Alió JL. Contrast sensitivity after laser in situ keratomileusis. $\mathcal{F}$ Cataract Refract Surg 1998;24:183-9.

22 Seiler T, Reckmann W, Maloney RK. Effective spherical aberration of the cornea as a quantitative descriptor in corneal topography. $\mathcal{F}$ Cataract Refract Surg 1993;19:155-65.

23 Pallikaris IG, Siganos DS. Excimer laser in situ keratomileusis and photorefractive keratectomy for correction of high myopia. F Refract Corneal Surg 1994;10:498-510.

24 Mulhern MG, Foley-Nolan A, O'Keefe M, et al. Topographical analysis of ablation centration after excimer laser photorefractive keratectomy and laser in situ keratomileusis photorefractive keratectomy and laser in situ keratomileusis

25 Pallikaris IG, Koufala KI, Siganos DS, et al. Photorefractive keratectomy with a small spot laser and tracker. $\mathcal{F}$ Refract Surg 1999;15:137-44.

26 Coorpender SJ, Klyce SD, McDonald MB, et al. Corneal topography of small-beam tracking excimer laser photorefractive keratectomy. F Cataract Refract Surg 1999;25:67484.

27 Tsai YY, Lin JM. Ablation centration after active eyetracker-assisted photorefractive keratectomy and laser in situ keratomileusis. f Cataract Refract Surg 2000;26:28-34. 